\title{
Characterization of suspended particulate matter emitted from waste rice husk as biomass fuel under different combustion conditions
}

\author{
Q. Wang ${ }^{1}$, T. Maezono ${ }^{1}$, P. Apaer ${ }^{1}$, Q. Chen ${ }^{1}$, L. Gui ${ }^{1}$, K. Itoh ${ }^{1}$, \\ H. Kurokawa ${ }^{1}$, K. Sekiguchi ${ }^{1}$, K. Sugiyama ${ }^{2}$, H. Niida ${ }^{1} \&$ S. Itoh ${ }^{1}$ \\ ${ }^{1}$ Graduate School of Science and Engineering, Saitama University, Japan \\ ${ }^{2}$ Hachinohe National College of Technology, Japan
}

\begin{abstract}
There are large quantities of waste rice husk, e.g. around 3 million tons are estimated as biomass waste every year in Japan. Air pollutants emitted from exhaust gases of rice husk incineration lead to very important environmental damage, not only because of the influence on global environment and climate, when released into the atmosphere, but also on human health due to local air pollution. Therefore, it is necessary to effectively utilize waste rice husk and to reduce air pollutants. In recent years, there is an increasing demand on the utilization of unused biomass instead of fossil oil fuel in combustors for farminggreenhouses heating during the winter season. This increase in the demand will increase the running costs. In general, since these combustors are small in size, there is lack of regulations or laws (e.g. the air pollution control act and the waste disposal and public cleaning law) in operation for their air pollution control. So far, small size combustors are characterized by their simplicity of structure and the low costs; therefore, they emit visible black carbon (elemental carbon) due to their poor combustion performance.

In this study, we investigated if fossil fuel can be substituted by waste rice husk in laboratory model combustion experiments. We evaluated the emission behavior of harmful air pollutants emitted from rice husk combustion by measuring carbonaceous and ionic composition of suspended particulate matter in the exhaust gases. From the analytical results we found that particulate mass concentrations can be reduced substantially at high temperature combustion. Fine particle size distribution is different with combustion conditions (e.g. smoldering combustion, flaming combustion). Ionic composition is mainly
\end{abstract}


constituted by $\mathrm{Na}^{+}, \mathrm{K}^{+}, \mathrm{Ca}^{2+}, \mathrm{Cl}^{-}, \mathrm{NO}_{3}{ }^{-}$and $\mathrm{SO}_{4}{ }^{2-}$ which are easily vaporized, followed by homogeneous nucleation and heterogeneous condensation of these inorganic vapors. As the results of our study, it can be suggested that we have to ensure stable combustion performance under suitable conditions in order to control less air pollutants emitted from biomass fuel although small size combustors are still not regulated.

Keywords: rice husk, small size combustors, fine particle size distribution, combustion conditions, carbonaceous and ionic composition.

\section{Introduction}

Currently, global warming is become increasingly evident in the global climate. Combustion of fossil fuel is generally admitted as the main responsible for global warming. Though, the use of fossil fuel is expected to increase in the future because of economic development and growth of population in developing countries (Saidur et al. [1]), hence, the only solution is zero-emission technology, that is, to reduce all possible emissions produced by human activities to zero (Dong et al. [2]). In order to achieve zero-emissions, it is important to apply a technology to utilize all unused biomass (Hansen et al. [3]; Ilipoulou et al. [4]).

Currently in Japan agriculture and forestry produce biomass residues from what a very small amount is used, instead, unused biomass is mostly being incinerated for disposal, due to its high cost of collection, transport, and storage and also the needs of energy that it implies. Moreover, the urgent countermeasures are required to reduce the air pollution from illegal waste biomass incineration.

It is estimated that only in Japan around 3 million tons of waste rice husk, which is the most common agricultural residue in the country, are wasted every year. Additionally, since rice is the staple food and regular part of the diet for almost half of the world population, an effective utilization of waste rice husk as biomass fuel will be an important countermeasure to global warming.

In recent years there is an increasing demand on the utilization of unused biomass instead of usual fossil oil fuel combustors for farming-greenhouses heating during the winter season. This increase in the demand will make prices to increase. In general, these combustors are small in size (Johansson et al. [5]) therefore existing regulations do not apply (e.g. the air pollution control act and the waste disposal and public cleaning law). So far, small size combustors are characterized by simplicity on their structure and low costs, however, visible black smoke and pollutants emitted due to the poor combustion performance and the lack of regulations (Simoneit [6]; Wiinikka and Gebart [7]).

In this study, the target is to investigate if waste rice husk can be used as biomass fuel based on our laboratory model combustion experiments. Firstly, we analyzed the chemical composition of agricultural waste rice husk and investigated its combustion characteristics. Then, the air pollutants emitted from waste rice husk combustion were measured by sampling suspended particulate 
matter and gases in the exhaust under the different combustion conditions. The possibility of reduction of these harmful substances is also investigated.

\section{Experimental methods}

\subsection{Composition analysis of waste rice husk samples}

Before our experiments, the waste rice husk samples (Kaneko Agricultural Machinery Co., Ltd., Japan) were prepared below $250 \mu \mathrm{m}$ by several sieves. The proximate and ultimate analyses of waste rice husk samples were carried out according to the Japanese industrial standard (JIS) method of JIS-M8812 and JIS-M8813.

\subsection{Evaluation method for combustion of the waste rice husk samples}

Combustion characteristics of waste rice husk samples were analyzed by the thermogravimetric/differential thermal analysis (TG/DTA), and under the following conditions: about $1.0 \mathrm{mg}$ of sample was heated at a rate of $5^{\circ} \mathrm{C} \mathrm{min}^{-1}$ starting from room temperature until $900^{\circ} \mathrm{C}$. A gas flow rate of $250 \mathrm{~mL} \mathrm{~min}{ }^{-1}$ was used; clean gas was used as the carrier gas for combustion.

\subsection{Evaluation of suspended particulate matter (SPM) in the exhaust gases}

\subsubsection{Air sampling method for the exhaust gases}

Biomass burning is an important source of primary fine particles in the atmosphere, which can influence the regional air pollution and human health. Recently, fine particles below $2.5 \mu \mathrm{m}$ in aerodynamic diameter $\left(\mathrm{PM}_{2.5}\right)$ either emitted from biomass burning or generated by photochemical reactions, are of great concern because of their effects over health and environment in Japan. Therefore in this study, evaluate the $\mathrm{PM}_{2.5}$ from combustion of waste rise husk. The collection devices of exhaust gases are shown in figure 1 . In order to evaluate the $\mathrm{PM}_{2.5}$ emissions for the combustor, exhaust $\mathrm{PM}_{2.5}$ were collected on quartz-fiber filters (35 mm $\varphi$, pallflex prpducts corp, 2500QAT-UP) and Teflon filters (35 $\mathrm{mm} \varphi$, pallflex prpducts corp, T8711A) using two air samplers which are called the $\mathrm{PM}_{2.5}$ personal sampler (NWPS-35HS, Sibata Scientific Technology Co. Ltd.). The quartz-fiber filter samples were used for carbonaceous composition analysis and samples, and the Teflon filters were used for ionic composition analysis. Gaseous components $\left(\mathrm{CO}, \mathrm{CO}_{2}, \mathrm{NOx}\right.$ and $\left.\mathrm{O}_{2}\right)$ were also evaluated by portable gas analyzer (PG-250, Horiba Co. Ltd.).

\subsubsection{Evaluation of particulate size distribution of suspended particulate matter in the exhaust gases}

In generally, coarse particles of suspended particulate matter are mainly having particle sizes larger than $2 \mu \mathrm{m}$ and it unable to instruction in to entering the respiratory tract by the nose, throat, and pharynges. However, fine particles with particle sizes below $2 \mu \mathrm{m}\left(\mathrm{PM}_{2.5}\right)$ are able to reach deeper parts of the respiratory 
system, including the air sacs of the lungs. While particles below $0.1 \mu \mathrm{m}$ (or ultrafine particles, $\mathrm{PM}_{0.1}$ ) are able to break into the alveoli and through the capillary beds reach the blood stream. Therefore it is necessary to analyze the size distribution of carbonaceous composition emitted from the combustion of waste rice husk. Particle size distribution, characteristics and chemical components of SPM were measured because of the influence on global environment and climate, when released into the atmosphere, but also on human health due to the local air pollution. The scanning mobility particle sizer (SMPS, Tokyo Dylec Co. Ltd, Model 3934) measured fine particle size distribution of waste rice husk combustion.

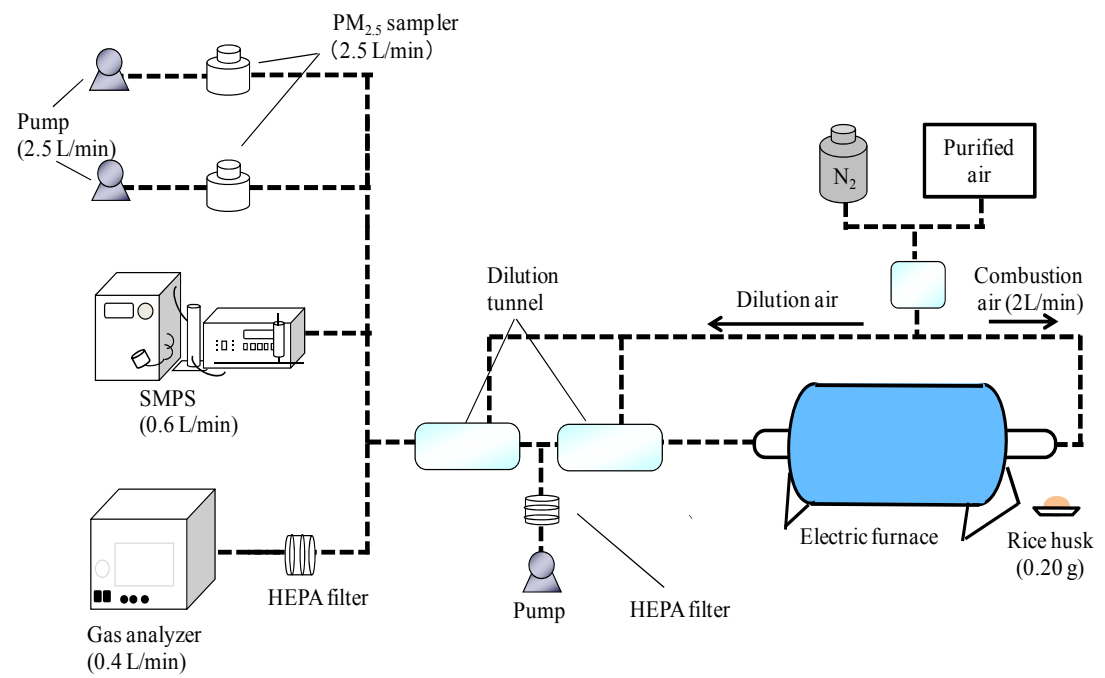

Figure 1: $\quad$ Air sampling setup for exhaust gases emitted from the combustor.

\subsubsection{Evaluation of carbonaceous composition of $\mathrm{PM}_{2.5}$ in the exhaust gases} Carbonaceous analysis was based on the IMPROVE method (Interagency Monitoring of Protected Visual Environment) by the thermo-optical carbon analyzer (thermo/optical carbon analyzer: Model 2001, Desert Research Institute) shown in table 1.

In this method (Bao L. et al. [8]), a $0.503 \mathrm{~cm}^{2}$ ( $8 \mathrm{~mm}$ diameter) punch aliquot of a sample quartz filter was heated at different temperatures of $120^{\circ} \mathrm{C}(\mathrm{OC} 1)$, $250^{\circ} \mathrm{C}(\mathrm{OC} 2), 450^{\circ} \mathrm{C}(\mathrm{OC} 3)$, and $550^{\circ} \mathrm{C}(\mathrm{OC} 4)$ for determination of organic carbonaceous components (OC1 OC4) in a helium atmosphere, and then at $550^{\circ} \mathrm{C}(\mathrm{EC} 1), 700^{\circ} \mathrm{C}(\mathrm{EC} 2)$, and $800^{\circ} \mathrm{C}(\mathrm{EC} 3)$ for determination of elemental carbon components $(\mathrm{EC} 1 \sim \mathrm{EC} 3)$ in an oxidizing atmosphere of $2 \%$ oxygen and $98 \%$ helium. The analysis was repeated two or three times for each sample for better accuracy. $\mathrm{PM}_{2.5}$ samples were collected at the flow rate of $2.5 \mathrm{~L} \mathrm{~min}^{-1}$ for the combustion out on each sampling with the $\mathrm{PM}_{2.5}$ personal sampler. 
Table 1: Protocol of IMPROVE thermal/optical method for carbonaceous analysis.

\begin{tabular}{ccc}
\hline Carbon fraction & Temperture $\left({ }^{\circ} \mathrm{C}\right)$ & Atmosphere \\
\hline OC1 & 120 & \\
OC2 & 250 & $\mathrm{He}$ \\
OC3 & 450 & \\
OC4 & 550 & \\
\hline EC1 & 550 & \\
EC2 & 700 & $\mathrm{He}: \mathrm{O}_{2}(98: 2)$ \\
EC3 & 800 & \\
\hline
\end{tabular}

\subsubsection{Evaluation of ionic composition of $\mathbf{P M}_{2.5}$ in the exhaust gases}

One half of the $35 \mathrm{~mm} \varphi$ Teflon filter was ultrasonically extracted with $5 \mathrm{~mL}$ ultrapure water (18.2M $\Omega$ milli-Q ultrapure water) for 20 minutes, in order to carry the ionic composition analysis. The concentrations of the following cations were measured: $\mathrm{Ca}^{2+}, \mathrm{Mg}^{2+}, \mathrm{K}^{+}, \mathrm{NH}_{4}^{+}$, and $\mathrm{Na}^{+}$and the following anions: $\mathrm{SO}_{4}{ }^{2-}$, $\mathrm{NO}_{3}^{-}$, and $\mathrm{Cl}^{-}$anions and cations were analyzed in two different ion chromatographs (IC, DX-100, Dionex Co. Ltd.).

\section{Results and discussions}

\subsection{Measurements in the composition of the waste rice husk}

The bulk composition of biomass in terms of carbon, hydrogen, and oxygen (CHO) does not differ much among different biomass sources. Typical dry weight percentages for $\mathrm{C}, \mathrm{H}$, and $\mathrm{O}$ are $30 \%$ to $60 \%, 5 \%$ to $6 \%$, and $30 \%$ to $45 \%$ respectively (Khan et al. [9]). Table 2 shows the composition analysis of waste rice husk. As the results of proximate analysis, it is indicated that ash contents are high in waste rice husk, while the carbon contents are low from the ultimate analysis of waste rice husk. It is mean that waste rice husk is low in its heating value. Therefore, it is necessary to find the suitable combustion conditions for effective utilization as biomass fuel of waste rice husk.

Table 2: $\quad$ Proximate analysis and ultimate analysis of waste rice husk.

\begin{tabular}{|c|c|c|c|c|c|c|c|}
\hline \multicolumn{4}{|c|}{ Proximate analysis (wt\%) } & \multicolumn{4}{|c|}{ Ultimate analysis (wt $\%)$} \\
\hline $\mathrm{M}$ & VM & Ash & $\mathrm{FC}$ & $\mathrm{C}$ & $\mathrm{H}$ & $\mathrm{N}$ & $\mathrm{O}$ \\
\hline 4.7 & 63.6 & 24.7 & 7.0 & 33.8 & 5.2 & 0.4 & 35.9 \\
\hline
\end{tabular}




\subsection{Combustion characteristics of the waste rice husk}

The TG/DTA thermogram for rice husk showed two well-defined peaks at $280^{\circ} \mathrm{C}$ and around $400^{\circ} \mathrm{C}$ (figure 2). These results show that waste rice husk achieves its thermolysis around $280^{\circ} \mathrm{C}$, where the more volatile components are burned while the carbonized fraction is burned at a higher temperature, around $400^{\circ} \mathrm{C}$. For this reason, the waste rice husk can only be combusted under the condition of the temperature range above $500^{\circ} \mathrm{C}$.

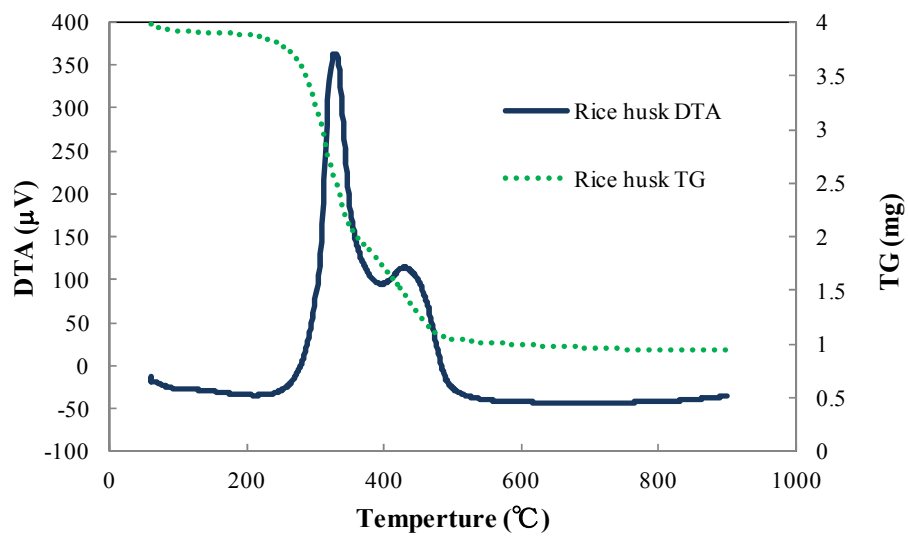

Figure 2: $\quad$ Pyrolysis and combustion profile of waste rice husk.

\subsection{Carbonaceous components in $\mathbf{P M}_{2.5}$ emitted from combustion waste rice husk at the different dilution ratio}

The effect of changes in the dilution ratio during waste rice husk combustion was investigated. Figure 3 shows the results of the different $\mathrm{PM}_{2.5}$ carbonaceous composition at dilution rates of 10, 15, and 20 times in the exhaust particles.

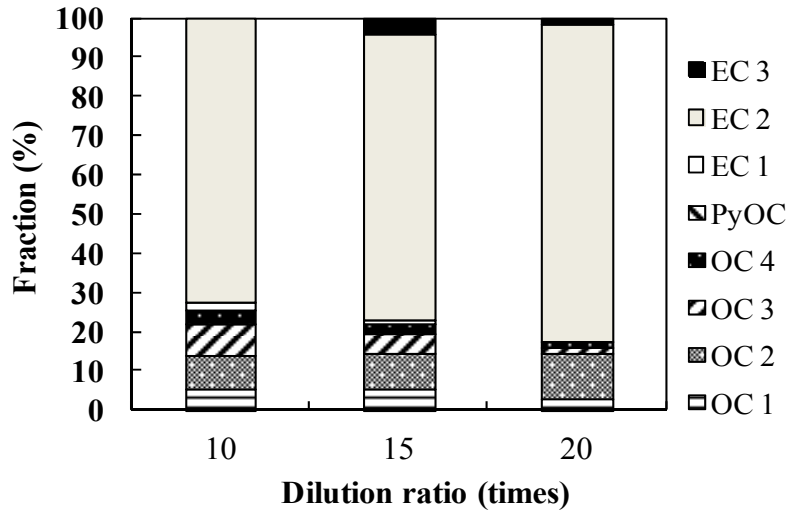

Figure 3: Fraction of carbonaceous components in $\mathrm{PM}_{2.5}$ emitted from combustion of waste rice husk at the different dilution ratios. 
As it can be seen, when the dilution ratio is increased, the particulate fraction of organic carbonaceous components are decreased. This decrease may be owed to the volatilization of semivolatile compounds when the dilution air forced the reach of new equilibrium concentrations in both phases. There may also be a small effect due to humidity in the exhaust gases however the amount of moisture in the system is so small that the effect is negligible.

\subsection{Air pollutants emitted from combustion of waste rice husk under the different combustion temperatures}

\subsubsection{Gaseous components and combustion efficiencies}

In this study, to simplify the combustion efficiency, we use the fact that $>90 \%$ of the carbon combusted in a fire is emitted in the form of $\mathrm{CO}_{2}$ and $\mathrm{CO}$, and $<10 \%$ of carbon is in species such as hydrocarbons and particulate carbon. With this in mind, the modified combustion efficiency (MCE) can be defined as the equation (1). According to the MCE, the combustion conditions can be categorized, when $\mathrm{MCE} \geqq 0.9$ indicates smoldering combustion and $\mathrm{MCE}<0.9$ indicates flaming combustion (Ward and Hao [10]).

$$
\mathrm{MCE}=\frac{[\mathrm{C}]_{\mathrm{CO}_{2}}}{[\mathrm{C}]_{\mathrm{CO}_{2}}+[\mathrm{C}]_{\mathrm{CO}}}
$$

The behavior of gaseous components during waste rice husk combustion under different temperatures $\left(500-1000^{\circ} \mathrm{C}\right)$ is shown in figure 4 . It can be found that all of gas concentrations show the similar behavior in two temperature ranges $500-600^{\circ} \mathrm{C}$ and $700-1000^{\circ} \mathrm{C}$.
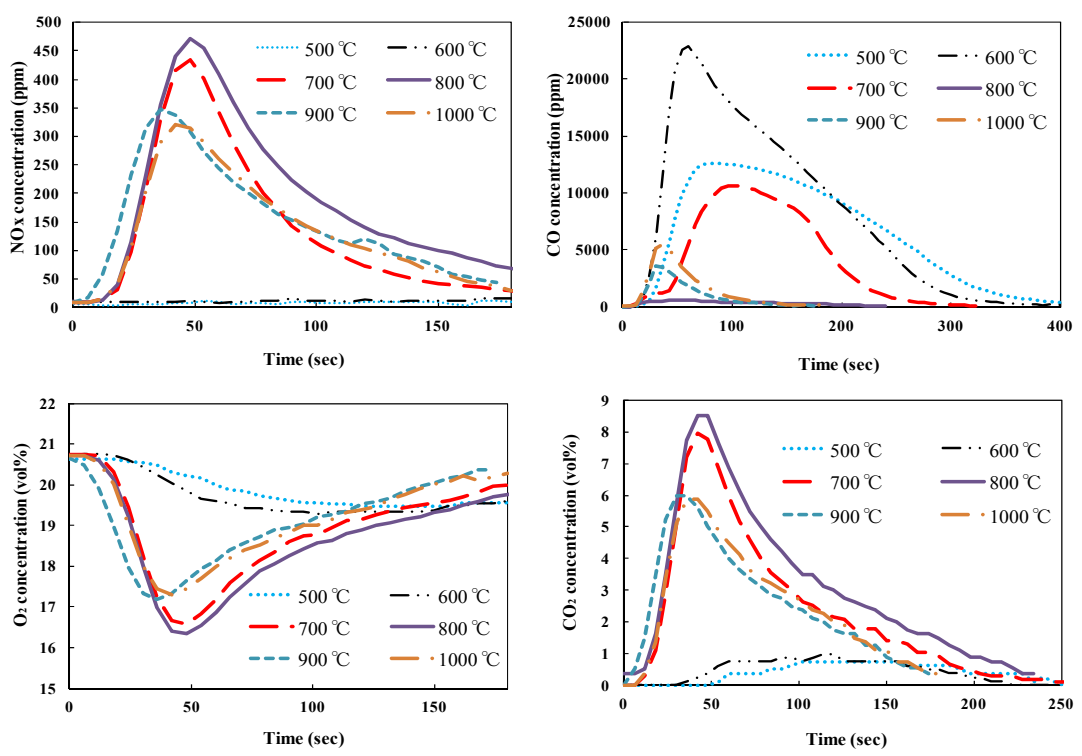

Figure 4: Gas components emitted from combustion of waste rice husk under the different combustion temperatures. 


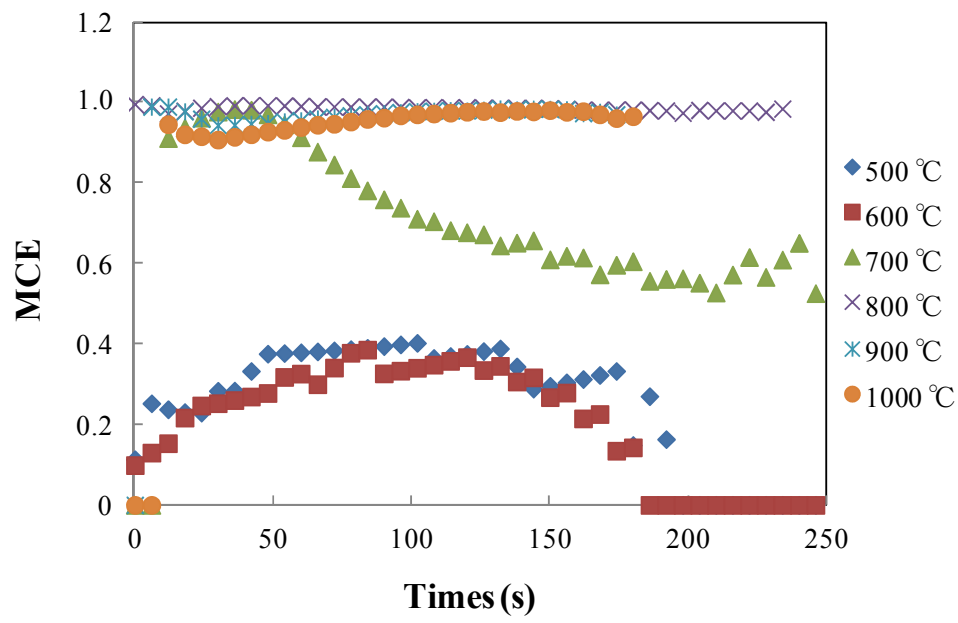

Figure 5: Combustion characteristics of waste rice husk under the different combustion temperatures.

\subsubsection{Fine particle size distribution}

Fine particle size distribution emitted under the different combustion conditions was measured with a SMPS. Figure 6 shows the fine particle size distribution of combustion rice husk under the different combustion temperatures. As shown in figure 6, it can be found that the peaks of fine particle number concentrations are around $100 \mathrm{~nm}$ under smoldering combustion $\left(500 \sim 600^{\circ} \mathrm{C}\right)$.

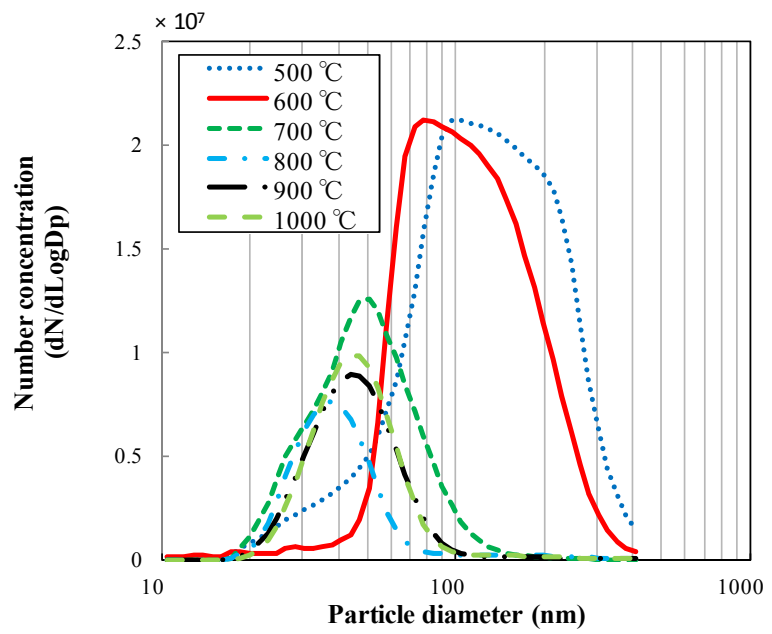

Figure 6: Fine particle size distributions and number concentrations of waste rice husk combustion under the different combustion temperatures. 
Fine particles were generated in larger numbers and at a more extensive range of diameters $(100 \sim 300 \mathrm{~nm})$ in smoldering combustion. On the other hand, under flaming combustion $\left(700 \sim 1000^{\circ} \mathrm{C}\right)$, the peaks of particle number concentrations are around $50 \mathrm{~nm}$, with lower number concentrations and at a narrower diameter range. It is indicated that fine particles under flaming combustion may be emitted less in smaller particle sizes than in those under smoldering combustion.

\subsubsection{Carbonaceous compositions in $\mathbf{P M}_{2.5}$}

The effect of combustion temperature on carbonaceous composition in $\mathrm{PM}_{2.5}$ was investigated. The results of carbonaceous composition analysis are shown in figure 7 .

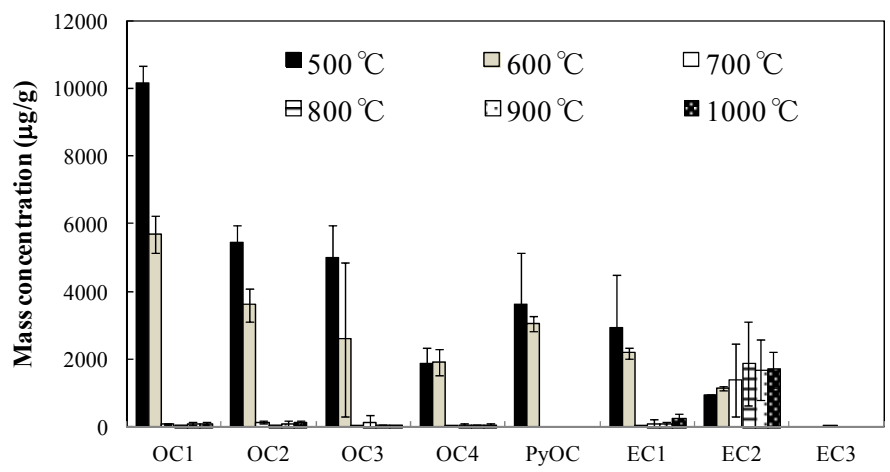

Figure 7: Carbonaceous compositions in $\mathrm{PM}_{2.5}$ from combustion waste rice husk under the different combustion temperatures.

OC compositions includes compounds like levoglucosan and methoxyphenol (Kuo et al. [11]), which are generated in the thermolysis of cellulose and lignin, levoglucosan is one of the water-soluble organic substances and it can contribute to cloud condensation nuclei and influence the optical properties of aerosol. In our results, $\mathrm{OC} 1$ was found at the highest concentrations in smoldering combustion which is mainly generated by biomass combustion at low temperatures $\left(500{ }^{\circ} \mathrm{C}\right)$. On the other hand, in smoldering combustion EC composition was dominated by EC1 (char-EC). Under flaming combustion, OC mass concentrations were decreased significantly, and EC concentrations were dominated by EC2 (soot-EC). From the results of total carbonaceous concentration $(\mathrm{OC}+\mathrm{EC})$, we can also see that carbonaceous concentrations in $\mathrm{PM}_{2.5}$ under flaming combustion were 10 times lower than under smoldering combustion.

\subsubsection{Ionic components in $\mathbf{P M}_{2.5}$}

It is shown that ionic concentrations in $\mathrm{PM}_{2.5}$ were high at $600^{\circ} \mathrm{C}$. The high concentrations of $\mathrm{Na}^{+}$and $\mathrm{SO}_{4}{ }^{2-}$ were determined at all combustion temperatures. In general, $\mathrm{K}^{+}$is an important component of biomass (Jones et al. [12]), since it 
is used in metabolic processes; therefore, this component can be used as a marker for biomass combustion contributing to air pollution. However, in our results, $\mathrm{K}^{+}$concentrations were low at all range of combustion temperatures, with an estimated emission of below $50 \mu \mathrm{g} / \mathrm{g}$ (ppmw) from waste rice husk burning in $\mathrm{PM}_{2.5}$ as the results shown in figure 8 .

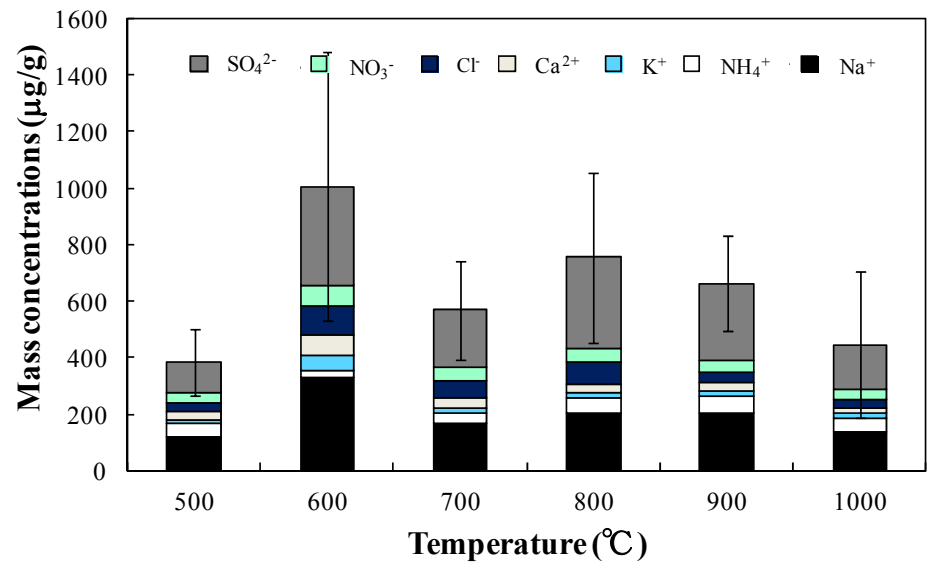

Figure 8: Ionic components in $\mathrm{PM}_{2.5}$ emitted from waste rice husk combustion under the different combustion temperatures.

As mentioned above, we have investigated the behavior of harmful air pollutants emitted from rice husk combustion by measuring carbonaceous and ionic components of suspended particulate matter in the exhaust gases. We will glad if the information of our study will be useful in development and production of small size combustors (Wang et al. [13]) for waste rice husk or other biomass fuels.

\section{Conclusion}

In this study, we evaluated the possibility of substitute fossil fuel by waste rice husk based on laboratory model combustion experiments.

According to the combustion characteristics of rice husk, it is possible to use as a biomass fuel if rice husk is combusted at the temperature range above $500^{\circ} \mathrm{C}$.

From analysis of gaseous components, it is indicated that flaming combustion $\left(700-1000^{\circ} \mathrm{C}\right)$ shows better in its efficiency than smoldering combustion $(500$ $\left.600^{\circ} \mathrm{C}\right)$.

From the results of fine particle size distribution and carbonaceous components, it is found that tenth part of carbonaceous particulate matter with smaller particle sizes may be only emitted under flaming combustion than under smoldering combustion. 
It can be suggested that air pollutants can be easily reduced if we can ensure stable combustion performance under suitable conditions especially for development of the small size combustors for various waste biomass fuels.

\section{Acknowledgement}

This study was supported by the Special Funds for Basic Researches (B) (No. 19404021, FY2007 FY2009 and No. 22404022, FY2010 2012) of Grantin-Aid for Scientific Research of the Japanese Ministry of Education, Culture, Sports, Science and Technology (MEXT), Japan.

\section{References}

[1] R. Saidur, E.A. Abdelaziza, A. Demirbasb, M.S. Hossaina and S. Mekhilef, A review on biomass as a fuel for boilers, Renewable and Sustainable Energy Reviews, 15, 2262-2289, 2011.

[2] Li Dong, Shiqiu Gao and Guangwen $\mathrm{Xu}$, No reduction over Biomass Char in the Combustion Process., Energy Fuels, 24, 446-450, 2010.

[3] Lone A. Hansen, Hanne, P. Nielsen, Flemming J. Frandsen, Kim DamJohansen, Steffen Horlyck and Asger Karlsson., Influence of deposit formation on corrosion at a straw-fired boiler., Fuel Processing Technology, 64, 189-209, 2000.

[4] E. F. Iliopoulou, E. V. Antonakou, S. A. Karakoulia, I. A. Vasalos, A. A. Lappas, and K.S. Triantafyllidis, Catalytic conversion of biomass pyrolysis products by mesoporous materials: Effect of steam stability and acidity of Al-MCM-41 catalysts, Chemical Engineering Journal, 134, 51-57, 2007.

[5] L. S. Johansson, C. Tullin, B. Leckner and P. Sjovall, Particle emissions from biomass combustion in small combustors, Biomass and Bioenergy, 25, 435-446, 2003.

[6] Bernd R.T. Simoneit, Biomass burning-a review of organic tracers for smoke from incomplete combustion, Applied Geochemistry, 17, 129-162, 2002.

[7] Henrik Wiinikka and Rikard Gebart, Experimental investigation of the particle emissions from a small-scale pellets combustor, Biomass and Bioenergy, 27, 645-652, 2004.

[8] Bao L., Sekiguchi K., Wang Q., Sakamoto K. Comparison of water-soluble organic components in size-segregated particles between a roadside site and a suburban site in Saitama, Japan, Aerosol Research and Air Quality, 9, 412-420, 2009.

[9] A. A Khan, W. de Jong, P. J. Jansens and H. Spliethoff, Biomass combustion in fluidized bed boilers: Potential problems and remedies, Fuel processing technology, 90, 21-50, 2009.

[10] Ward D. E and Hao W. M., Air toxic emissions from burning of biomass globally-preliminary estimates, Proceedings of Air and Waste Management Assoc. 85th Annual Meeting and Exhibition, 1992. 
[11] Li-Jung Kuo, Patrick Louchouarn and Bruce E. Herbert, Influence of combustion conditions on yields of solvent-extractable anhydrosugars and lignin phenols in chars: Implications for characterizations of biomass combustion residues, Chemosphere, 85, 797-805, 2011.

[12] J. M. Jones, L. I. Darvell, T. G. Bridgeman, M. Pourkashanian and A. Williams, An investigation of the thermal and catalytic behavior of potassium in biomass combustion., Proceedings of the Combustion Institute, 31, 1955-1963, 2007.

[13] Wang Q., Maezono T., Q. Chen, P. Apaer, Y. Wang, L. Gui, D. Niida, N. Mitsumura, M. Domon, I. Fujiwara and N. Yamaguchi, Basic study on combustion characteristics of waste rice husk and emission behavior from a new-type air vortex current combustor, Sustainable Chemistry, Ecology and the Environment, 154, 199-210, 2011. 